\title{
IUFOST2006/557 \\ Influence of the composition and the structure of fruit preparations on the aroma release and diffusion
}

\author{
G. Savary ${ }^{\mathrm{a}}$, E. Guichard ${ }^{\mathrm{a}}$, J.-L. Doublier ${ }^{\mathrm{b}}$ and N. Cayot ${ }^{\mathrm{a}}$ \\ ${ }^{a}$ INRA - ENESAD Joint Research Unit : Flavor, Vision \& Consumer Behaviour, 17 rue Sully - BP 86510, \\ 21065 Dijon, France

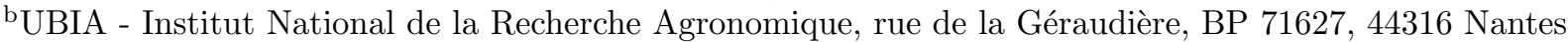 \\ Cedex, France \\ gsavary@dijon.inra.fr
}

Most of processed foodstuffs are known to contain texture agents which are involved in aroma release. For example, the headspace concentration and the perceived flavor of benzaldehyde and limonene were significantly reduced with increasing firmness of gels prepared from carrageenan, gelatin or starch (Carr et al., 1996).

The main objective of the present study was to understand the effect of the structure and the composition of the food matrix on the release of aroma compounds. For this purpose, fruit preparations have been chosen as model systems. Such products contain polysaccharides as gelling agents, generally pectin, in combination with modified starch in the presence of sucrose and in acidic pH. Four different models were developed by modifying either the composition or the concentration in gelling agent. They were flavoured with a strawberry aroma containing 17 molecules.

In a first step, the structure of the models was characterized at macroscopic scale by means of rheological measurements, and at microscopic scale by measuring the swelling index and performing microscopic observations.

To investigate aroma release, an instrumental approach has been favoured rather than a sensorial one in order to study separately the kinetic phenomena that can occur during the release, especially the diffusion and the mass transfer of aroma compounds. The self-diffusion coefficient into the matrix was measured by way of the DOSY-PGF-NMR spectroscopy (Savary et al., 2006a) and the global mass transfer by APCI-MS. On another hand, the partition coefficient was obtained using the Phase Ratio Variation method (Savary et al., 2006b). In this presentation, it is illustrated how these different methods can be combined with the structural descriptions performed at different scales to interpret the effect of the structure of the gel on aroma release.

REFERENCES

Carr J., Baloga C., Guinard X., Lawter L., Marty C. and Squire C. (1996). The effect of gelling agent type and concentration on flavor release in model systems. In Flavor-Food interactions; Leland, Ed.; ACS: Washington, DC, 98-108.

Savary G., Guichard E., Doublier J.L., Cayot N. and Moreau C. (2006a). Influence of ingredients on the self-diffusion of aroma compounds in a model fruit preparation: an NMR-DOSY investigation. Journal of Agricultural and Food Chemistry, 54(3), 665.

Savary G., Guichard E., Doublier J.L. and Cayot N. (2006b). Mixture of aroma compounds: determination of partition coefficients in complex semi-solid matrices. Food Research International, 39, 372. 